\title{
Impact of Determinants on Student Performance towards Information Communication Technology in Higher Education
}

\author{
Arif Sari \\ Dept. of Management Information Systems, European University of Lefke \\ Gemikonagi, via Mersin 10 Turkey, Turkish Republic of Northern Cyprus \\ Tel: 90-533-847-7936 E-mail: arifsarii@gmail.com
}

Accepted: February 5, 2012 Published: March 17, 2012

Doi:10.5296/ijld.v2i2.1371 URL: http://dx.doi.org/10.5296/ijld.v2i2.1371

\begin{abstract}
New teaching and learning techniques are developing day by day with the support of information technology and the Internet. Many universities take the advantage of support of information technologies on teaching and learning environments. Each individual's physical, mental and emotional skills are different. It is emphasized that, more importance are given to individuals performances while they are in groups in those places where the traditional teaching approaches is dominated. At this point, individual performance of individuals and their different learning abilities could not be evaluated alone and left in the background. In these places, it is also stated the importance of learning in groups but not individually. The attitude of an individual towards the computer could be defined as a positive or negative view of the individual on the computer technology or the computer-supported applications. In the development of the attitude of the students, their personal characteristics, perception of computers, frequency of their use of computers, their sex, age and previous experiences play an important role. Some experts find it striking that when attitudes towards the computers are investigated, the researchers are concentrated more on teachers and teachers-to-be, while studies on establishing the attitude of students are limited in number. For that reason, this study focuses on impact of determinants of student performance and evaluates this performance through an exploratory research.
\end{abstract}

Keywords: student performance, ICT technology, higher education, motivation, determinants. 


\section{Introduction}

Development of information and technology in today's world affects social and economic areas and creates substantial changes in the field of education. Progress achieved in basic skills has had an impact on the development of modern technology and the new methods of production, transport and communication which have recently emerged. Information and Communication Technologies (ICT), which include newer digital technologies such as computers and Internet, have been touted as one of the potentially powerful enabling tools for educational reform. Different ICT tools expand access to higher education and strengthen the relevance of higher education, increase the quality of education and performance when used appropriately. However, effective integration of ICTs into the educational system is a complex process which involves participation of institutional readiness, instructors and long term investments.

As it is mentioned before, ICT provides opportunity for asynchronous learning and expand access to higher education which also means that anytime-anywhere service. Online users may access to course materials 24 hours, 7 days a week. Other ICT technologies, such as teleconferencing, allow geographically dispersed students to receive instruction simultaneously. The materials about the courses on the web can also be accessed by an unlimited number of people at anytime, from anywhere.

Because of many reasons, higher education institutes implement ICT technologies for teaching purposes. Successful implementation of ICT relies on variety of factors such as instruction participation, institutional readiness, applicable course curriculums and designs etc.. In the literature, studies conducted about ICT measured performance of instructors, and how the instructors can be more effective on teaching materials to students. Many of the researchers overlap or revised the implementation of ICT on similar studies which eventually have two key participants, the "teacher" and the "student". In fact, researchers were focusing on the "teacher" factor mainly, and skipping the "student" which is most important participant of the studies.

The successful implementation of ICT relies on "teacher" as well as "student" factor. A critical evaluation and investigation of determinants, which shapes student characteristics plays a key role of proper implementation of ICT. In light of this successful implementation, increase on the performance of students and effectiveness of ICT technology will be inevitable. For that reason, this study investigates the impact of determinants that shapes students characteristics towards ICT technology.

In the following sections of this study, higher education concept, higher education institutes and role of ICT in higher education concepts are explained briefly.

\section{Higher Education}

Education can be explained with a simplest definition as; the art of changing behaviors. It is a systematic program sustained to changed behaviors and eliminates undesired attitudes. Education is the basic element of growing qualified people and forming personality and character of people. Education changes person's characteristics, and cause to expose new 
attitudes and behaviors. These attitudes and behaviors provide autonomy to the person among the society. Each person becomes different because of these attitudes and behaviors as a product of the education atmosphere. The importance of education always increases especially in the last century and made education compulsory and continuing.

Education is whole activities that provide people adapt life rationally and efficiently. Teaching is the process of forming the behaviors of individuals and groups in a planned way, which a specific aim and system (Librarie Larausee, 1986).

On the other hand, education gives the feature of being qualified to the qualified people processing the product. Education enlarges views and opinions, provides new opportunities and enables employment in business market. People productivity can be affected in education because of several reasons. Education has a cost and this feature indicates that, the productivity can change according to economic and social changes. Some investments should be made in advance before trying to apply an education program indeed. In this case, enlarging the current, infrastructure may be more expensive than building it again. On the other hand, productivity of education may be low in societies which are not organized in order to benefit from information and capabilities of the individuals.

Education is a part of culture that cannot be separated from it. Therefore, measuring productivity with numbers is hard and it is impossible sometimes. One of the most important aims of the education; is to contribute to increase life standards of the society. Accomplishing this service and aim requires the education to be flexible and open for various changes. In the basis of improvement, there are positive changes in economic, politic and social areas.

The first thing we recall after hearing what education is, to be conscious behavior change of an individual all through his life. It is expected a change at the behaviors of people who have passed from education process. It is known that purposes, information, behaviors and ethnic measures of people are changed through education. There has been lots of description of education. In some of those description, It have been stated the general and comprehensive meaning of education and in the others it has been stated that the meaning that is revealed by an obvious plan or program. These are the some of the general and comprehensive descriptions:

It is behavior changing process in general meaning.

It is the social processes which is effective for individual to gain community standards, beliefs and living ways in extensive meaning.

It is the entire processes of the person in which he developed skills, manners and other behavior skills that has worth in community.

It is the total of processes of individual in which he gets ability, leading and other behavior views that is worthful for community.

\subsection{Higher Education and Higher Education Institutes}

Higher education is an education process built on secondary education and it had remarkable differences from other education processes. Higher education is organizations providing 
education and research services following secondary education and is made of high schools enabling to enlarge intellectual power, universities and technical schools.

Gücluol (1996), states that higher education is the education and learning provided by either private or public organizations, for people who have completed their secondary education and are willing to continue their education.

The higher education sector in most of the countries consists of a university and a non-university sector. Universities are institutions with the authority to grant degrees. They can offer courses and degrees in multi-disciplines or in a limited number of specialized areas. The universities can be private or public in terms of ownership and sources of financing.

The non-university sector consists of technical institutions offering courses in professional subject areas, training colleges and specialized institutions offering programmes of study and carrying out research, as well as institutions engaged in policy and planning support to the education sector.

Higher education organizations have the role of expertise schools in forming comfort society. In this sense, higher education has determinative role in occupational life and personal development of people. Universities; can be defined as; an organization which produces skilled manpower, has people get a job, enlightens the society, and serves other related activities and services.

The higher education institutions are the ones that provide higher level of information, having added value activities for the society which do educations searches. So the basic principles and aims of higher education are; growing the necessary manpower, providing a well educated manpower in industry area, rationalization in industry, agriculture and health services and carrying out studies and program that will enable increase in production.

\subsection{Role of ICT in Higher Education and Information Society}

A new demand for skills required by an industrial economy, emergence the interconnected digital world transformation which leads people to become more creative and respond to an ever changing set of problems. Education systems have in general been insufficient and slow to respond to this new demand. The education system have responded partially to this demand by focusing on technical ICT skills and only few of education institute considered the full range of " $21^{\text {st }}$ century skills" which ask students to think creatively, solving problems, effectively and efficiently communicate, identify and analyze existing information, use this information properly and create knowledge. In order to respond to this certain demand in the society completely, those role players, (student and teacher) should be ICT proficient. However, neither students nor instructors are completely ICT proficient in many higher education institutes.

ICT proficiency is the ability to use digital technology, communication tools and/or Networks appropriately in order to solve information problems in order to function in an information society. This includes the ability to use technology as a tool to research, organize, evaluate and 


\section{Al Macrothink}

communicate information and the possession of fundamental understanding of the ethical/legal issues surrounding the access and use of information.

The Internet, computers and related technologies become more ubiquitous day by day. The technological literacy or ability to use ICTs effectively and efficiently represents a competitive edge in an increasingly globalizing job market. ICT becomes very popular and in our technology-infused and competitive world, those who are ICT literate have power-"power of autonomy, power of enlightenment, power of self-improvement and self-assertion, power over their lives and their families' future," as Georgian, V. (2002) has stated.

\section{Research Methodology}

The research methodology falls into different sections and case study covers university students. In the following sections, a research model will be formulated and hypothesis will be declared. Later on, these hypotheses will be tested through collected information analyses. Collection instrument is "questionnaire". Each and every step is explained briefly in the further sections of this study.

\subsection{Research Model Formulation}

Figure 1 shows the general research model formulation. The impact of determinants which affects the student's performance through ICT technology is divided into two (2) categories of variables which are Internal and External variables. As it is shown below, internal variables are classified as demographic and psychographic, external variables classified as social, cultural and technological variables. In this study, two (2) hypotheses are formulated through the impact of internal and external variables on student performance towards ICT Technology. The variables which mentioned above would be discussed clearly later sections of this study.

There are 4 different types of variables exist which are classified as, dependent, independent, moderating and intervening variables. In this research, some of these variables are shown and classified in the Figure 1. 
Figure 1. Dependent and Independent Variables Classifications

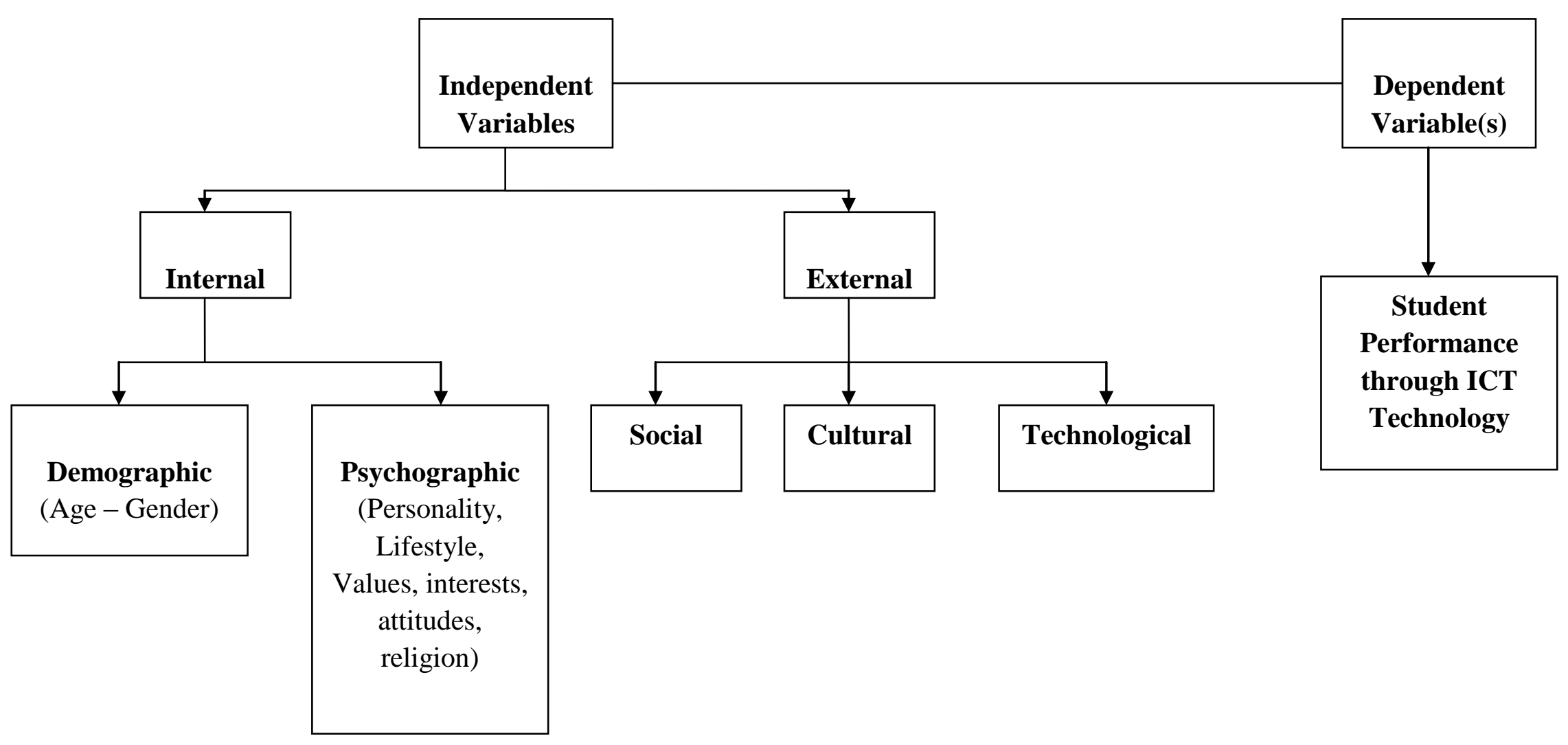


The Figure 1 above is showing the classification of the variables during the formulation of the hypothesis.

The variables which are classified under the Psychographic variables referring to any other attribute related to personality, lifestyle, values, interests or attributes. These factors consider various influences on a student's performance towards ICT technology.

Technological Variables; was developed to measure and categorise students based on ownership, use patterns and attitude towards different technologies. A concrete example would be humanity's attitude towards the Internet. There are distinct differences between frequent Internet users and those who seldom use it. Most experienced Internet users are more affluent and tend to be more optimistic towards modern technology than those who are not experienced. A newly recruited ICT user feels uncomfortable compared to those who use them often.

Social variables and Cultural variables affect the performance of the students externally. In some cases, students come from overseas countries or underdeveloped countries which have dominated by strict rules against technological innovations. It may cause ignorance against this technology and cause lack of performance.

Demographic variables are the main variable for this research. Student's age ratio can affect the implementation of ICT and performance outcomes. Age factor may affect the learning performance, motivation and duration directly.

\subsection{Research Objectives and Hypothesis}

This research focuses on the Impact of Determinants on Student towards ICT Technology in Higher Education. In order identify the impact of internal variables (demographic and psychographic variables) on student's performance through ICT technology;

H1: There is a significant impact of internal variables (demographic and psychographic variables) student's performance through ICT technology.

To identify the impact of external variables (social, cultural and technology variables) on student's performance through ICT technology;

H2: There is a significant impact of external variables (social, cultural and technology variables) on student's performance through ICT technology.

\subsection{Range of Study and the sample selection}

This study focuses the students of European University of Lefke in Cyprus. Students from different faculties and department are participated in this project. The total number of students who participated in this project is 200 . The total population of the university is approximately 3150. The faculties which involved into this project are the following;

Faculty of Economics and Administrative Sciences, Faculty of Architecture and Engineering, Faculty of Communication, Faculty of Arts and Sciences and Faculty of Tourism and Health Management. Different departments of students of these faculties participated in this research. 


\subsection{Data Collection}

In this research, two different sources are used to accomplish the objectives of this study. The primary sources and the secondary sources.

The primary source for this research is the information collected through questionnaires. The information obtained from this source has provided statistics, which measure the students' performance towards ICT technology in Higher Education.

The secondary sources will be gathered from references and published books, journals and information available on the internet. Additionally, some data obtained from the particular websites from the Internet.

\subsection{Sample Plan \& Sampling Technique}

The following sample units have been selected based on the following methods and the sample units ought to have requisite criteria to get selected for the study.

Should be a student of European University of Lefke,

Should be registered to one of the programs at European University of Lefke,

The participants should be aware of the ICT technology,

The participants should be able to participate in ICT classes.

A simple random sampling has been used to select target respondents for this study. The students of EUL have been informed on the purpose of the study and the willing students participated in the study. Responders for the survey were randomly selected 100 individual people from EUL. The sample population include only students as well as those students who work outside as well. In addition to that, 100 students would be divided into 2 groups, and ICT technology oriented class sessions are applied only 1 of the group.

\subsection{Sample Size}

The sampling size is used for this research study is Two Hundred $(\mathrm{N}=100)$.

\subsection{Collection Instrument}

The instrument used for collecting the primary data is questionnaire. The questionnaire is a structured questionnaire. Selective questions were asked and respondents just ticked appropriately. Open ended questionnaire was used for the pilot study and the result of the open ended questionnaire was used to formulate the closed end structured questionnaire.

\subsection{The Design of the Questionnaire}

The contents of the questionnaires were mainly derived from the literature review. In addition, from some research and studies conducted in this field.

The questionnaire is developed in English but because of the student's profile at University of Lefke; the questionnaire is also translated into Turkish. This action has granted two main factors for the questionnaire; 
Firstly, helped in saving time spent with respondent to translate and explain the questionnaire elements. Secondly, it guaranteed the highest level of understanding of the questionnaire items and the ideal amount of freedom for answering.

\subsection{Questionnaire Contents}

The questionnaire contains totally 10 questions. The first 3 questions were designed to gather main general information of the respondents such as age, sex, nationality, occupation and monthly income. The question number four to question number eight containing the questions about the frequency of involving into ICT course sessions. Especially, question number six, is measuring the involvement to ICT course sessions according to different fields of science.

The last 2 questions were designed to examine the student's satisfactions and perceptions against ICT involved class sessions and their recommendations about ICT technology. The question number 9 is 5 point scale designed question and measuring the replies in five ranks. This question was measuring the actual reason of like or dislike of ICT class sessions by students. It also shows the personality, perceptions and the student behaviour against ICT Technology. The more details about this question are given in the "Findings" section of this study.

The questionnaire in the study was designed for the Bachelor students who are studying in any faculty and department of European University of Lefke. Single questionnaire was given to each respondent which containing the questions about his or her perceptions, and particular behaviour which determining the influencing factors of ICT involvement. The questionnaire contained questions used to determine the demographic distribution as well as perceptions and behaviours of the respondents. Question 1 was based on the age distribution of the respondents; Below 20, 21-30, 31-40, 41-50, and above 50 years. Question 2 was based on the gender of the respondents; Male or Female. Question 3 was based on the nationality of the respondent, Turkish Cypriot, Turkish, African, Arabic and Others. Question 4 was designed based on the occupation of the respondents, which could be; Student, Private, Business, Housewife. Question 5 was designed based on the Monthly Income of the respondents in terms of Turkish Liras (TL) and which can be; Below 1000, 1001-2000, 2001-3000, 3001-4000 and above 4000. Question 6 was based on the different types of ICT practices and it was aiming to find out the most frequently done ICT application. Question 7 was designed to find out involvement into the ICT class frequency of students which is limited with last 12 months time period and can be; Once, 2-4 weeks, 5-10 weeks, More than 10 weeks. Question 8 is designed for to measure the amount of money spent on technology in terms of Turkish Lira and which can be; Below 50, 51-100, 101-150, 151-200 and Above 200. The Question 9 is designed based on the "Five Points Likert" scale. The respondents were asked to rank their interests (against involving ICT classes) using highly agrees as the highest and highly disagrees as the least. Question 10 was designed for to measure the recommendation of ICT class sessions, by respondents to their relatives and friends which can be; Definitely Recommend, Somewhat recommend, No Comments, Do Not Recommend, Not at All. 


\section{Findings \& Hypothesis Testing}

At the Hypothesis formulation section of this study, the following hypothesis have been formulated which are;

H1: There is a significant impact of internal variables (demographic and psychographic variables) student's performance through ICT technology.

To identify the impact of external variables (social, cultural and technology variables) on student's performance through ICT technology;

H2: There is a significant impact of external variables (social, cultural and technology variables) on student's performance through ICT technology.

According to the answers we gathered from the respondents and analyzing of these data, results are showing us that, $\mathrm{H} 1$ and $\mathrm{H} 2$ are correct. Because demographic and psychographic variables affecting the respondents behaviour towards ICT involvement in this study. Table 1, showing the rankings of the ideas which gathered from the questionnaires of respondents.

\begin{tabular}{|l|l|l|l|l|l|}
\hline S.No & Statements & Score & $\begin{array}{l}\text { S. } \\
\text { Score }\end{array}$ & Rank & $\begin{array}{l}\text { Agreement } \\
\text { Level }\end{array}$ \\
\hline 1. & I involve into ICT classes because I am single & 242 & 12.1 & 17 & Disagree \\
\hline 2. & $\begin{array}{l}\text { I involve into ICT classes because I am } \\
\text { married }\end{array}$ & 241 & 18.2 & 4 & Disagree \\
\hline 3. & $\begin{array}{l}\text { I involve into ICT classes because I have } \\
\text { children }\end{array}$ & 269 & 13.5 & 16 & Disagree \\
\hline 4. & $\begin{array}{l}\text { I involve into ICT classes because I am } \\
\text { educated }\end{array}$ & 277 & 13.9 & 13 & Disagree \\
\hline 5. & $\begin{array}{l}\text { I involve into ICT classes due to my } \\
\text { occupation }\end{array}$ & 370 & 18.5 & 3 & Highly \\
Agree
\end{tabular}




\begin{tabular}{|l|l|l|l|l|l|}
\hline 13. & $\begin{array}{l}\text { I } \text { involve into ICT classes because it is } \\
\text { suitable to my culture }\end{array}$ & 284 & 14.2 & 11 & Agree \\
\hline 14. & $\begin{array}{l}\text { I involve into ICT classes because it is useful } \\
\text { for my work culture }\end{array}$ & 341 & 17.1 & 6 & $\begin{array}{l}\text { Highly } \\
\text { Agree }\end{array}$ \\
\hline 15. & $\begin{array}{l}\text { I involve into ICT classes because it helps me } \\
\text { to align with my culture }\end{array}$ & 282 & 14.1 & 12 & Agree \\
\hline 16. & $\begin{array}{l}\text { I involve into ICT classes because the } \\
\text { technology save my time and money }\end{array}$ & 356 & 17.8 & 5 & $\begin{array}{l}\text { Highly } \\
\text { Agree }\end{array}$ \\
\hline 17. & $\begin{array}{l}\text { I involve into ICT classes to show I am a tech } \\
\text { savvy (lover of technology) }\end{array}$ & 373 & 18.7 & 2 & $\begin{array}{l}\text { Highly } \\
\text { Agree }\end{array}$ \\
\hline 18. & $\begin{array}{l}\text { I involve into ICT classes because it is the } \\
\text { latest technology on commerce }\end{array}$ & 387 & 19.4 & 1 & $\begin{array}{l}\text { Highly } \\
\text { Agree }\end{array}$ \\
\hline
\end{tabular}

Table 1. Agreement Level of Respondents

According to that information, involvement of ICT affected due to occupation, education, and because of the popularity of this technology in education market and as well as people characteristics effect the involvement into ICT sessions. This is showing that, both internal and external variables have a significant impact on mobile commerce. The findings show us that students do not spend too much money on the education related technology. However, the interactive services which requires technology, such as chatting, games, etc. are most popular technological services used by the respondents. On the other hand, majority of respondents (78\%) participates 5-10 weeks in ICT sessions. Another important finding is the lack of ICT infrastructure in the region. Minority of respondents are not satisfied from ICT classes and believe that ICT infrastructure is not sufficient at the present education environment.

\section{Conclusion \& Recommendations}

This study has conducted at European University of Lefke, and it has limitations because of limited resources, time and population. It must be stated that, the research outcomes may vary if it conducts on different regions of the country with different populations.

Research outcomes may rely on the respondent's profile, or different characteristics of the respondents. This specific research is conducted mainly with the university student's participation. The student's perception against ICT involvement and monetary income may affect the outcomes of the study as it is a requirement for availability of technology.

Students may involve into ICT sessions more extensively. ICT applications can become more popular by introducing them more frequently to students and through measuring learning outcomes and increasing effectiveness. Student ideas and behaviour indicate us that, they involve this technology and mainly they are lover of this technology, for that reason they are using this technology. This study was conducted on a small region of the country, but it can be a sample for to analyze the probable student behaviour and perception against ICT sessions and entails to provide better services or improve existence services in different regions. The findings can show us that, respondents are technology savvy and like technological improvements and developments. Some limitations may exist such as lack of infrastructure and instructor's compatibility or incompatibility of students to ICT classes are some of the handicaps for ICT involvement. The study can be conducted by considering what type of ICT 
application services preferred by students and under what circumstances students will rely on these services. Because some of the students, especially in such a region which ICT infrastructure is not completely functions, the ICT technology cannot go further than a simple technology concept and it cannot be used as a learning/teaching tool for educational institutions as well as students. If higher education institutions are to accomplish their mission of preparing students for success in today's world, then clearly they must address the growing demand for ICT literacy.

\section{References}

Atkinson R. L., Atkinson R. C., Smith E. E., \& Bem D. J. (1993) Introduction to Psychology $\left(11^{\text {th }}\right.$ edition) Fort Worth TX: Harcourt Brace Jovanovich.

Clark D. Learning domains or bloom's taxonomy, 1999. Available at: http://www.nwlink.com/ donclark/hrd/bloom.html. Accessed 15/06/2010

Dede, C. 1993a. Beyond Distributed Multimedia: A Virtual Forum for Learning.ED Journal 7, 8 (September), 14-18.

Distance Learning Glossary. United States Distance Learning Association. Available at: http://www.usdla.org/html/resources/dictionary.htm\#d. Accessed 22/08/10.

Eric J. MacLaughlin, Robert B. Supernaw, Kellee A. Howard. (2004). "Impact of Distance Learning Using Videoconferencing Technology on Student Performance" American Journal of Pharmaceutical Education 2004, 68 (3) Article 58.

Green, K. C. (2000, October). Struggling with IT Staffing. Encino, CA: The Campus Computing Project.

Güçlüol, K. (1996). Üniversitelerin temel sorunları: Çağdaş eğitim-çağdaş üniversite, üniversitelerimizin gelişmişlik durumu. Ankara: Türkiye Cumhuriyeti Cumhurbaşkanlığı Yayınları.

Jones, G. (1997). Cyberschools. Englewood, CO: Jones Digital Century, Inc.

Kamptis, Ewa., Swail, S.W,. (2001) Distance Education \& Accreditation-Riding a Tide of Opportunity, Publication courtesy of Educational Policy Institute.

LIBRARIE Larousse, Büyük Larousse Sözlük ve Ansiklopedisi, İstanbul: Gelişim Yayınları A.Ş., 1986.

Marchese, T. (1998, May). "Not-So-Distant Competitors: How New Providers Are Remaking the Postsecondary Marketplace." AAHE Bulletin, 50(9), pp. 3-7.

NUA. (2000) How Many Online? Information from NUA Internet Surveys online. (www.nua.net/surveys/how many_online/index.html).

Pavlov R., Dochev D., Virtual Campuses - Developments and Lessons Learnt. MTA SZTAKI Centre of Excellence project ICAI-CT-2000-70025, Bulgaria, April 2002, 5 p. 
U.S. Department of Education (1999). Distance Education at Postsecondary Education Institutions: 1997-98. A PEQIS Report. Washington, DC.

Lawrence, S. et al. (2001). Persistence of Web References in Scientific Research. Computer. 34, 26-31. http://dx.doi.org/10.1109/2.901164

Smith, Joe, (1999), One of Volvo's core values. [Online] Available: http://www.volvo.com/environment/index.htm (July 7, 2007)

Strunk, W., Jr., \& White, E. B. (1979). The elements of style. (3rd ed.). New York: Macmillan, (Chapter 4).

Van der Geer, J., Hanraads, J. A. J., \& Lupton R. A. (2000). The art of writing a scientific article. Journal of Scientific Communications, 163, 51-59

Gregorian, V. (2002, June 4). Keynote address presented at the White House Conference on School Libraries. 